and I firmly believe it will be found to conduce quite as much as any other method to the absence of blood-poisoning, and more than any other to rapidity of convalescene:

Let me also call attention to the use of this material for injection into the bladder in cystitis. When the mucus and urine are inclined to decompose and to become ammoniacal, this compound acts a charm. I have found it invaluable if any irritation arise after litholapaxy.

\section{ON HYSTERECTOMY.}

Read in the Section of Obstetric Medicine at the Annual Meeting of the British Medical Association in Worcester, August 1882.

BY G. GRANVILLE BANTOCK, M.D.,
Surgeon to the Samaritan Hospital, etc.

THE subject to which I wish to direct your attention to-day is that of Hysterectomy. What I mean by this term is the removal by abdominal section of a fibroid or fibrocystic tumour of the uterus, whether involving a part or the whole of the body of the uterus, or not. It is scarcely necessary, on an occasion like this, that I should defend the nomenclature at any length. I would merely point out that the term hysterectomy, used by some authors, has already been appropriated to Simpson's operation of division of the cervix; that Freund's operation describes the complete extirpation of the uterus, and Porro's the removal of the body of a pregnant uterus, together with both ovaries. Now, the operation of extirpation of a fibroid or fibrocystic tumour varies so much in its details, that it is impossible to find a name, based on anatomical considerations, that will include every case; yet the term hysterectomy appears to me to meet the essentials of the case, and I accept it as sufficiently comprehensive and descriptive. Besides, the best names are not those which most closely and correctly describe any operation, as in two of the instances just mentioned, and in others that will occur to you.

Forty years ago, this operation was unknown. It is true, however, that the abdomen had been opened more than once, viz., even as early as 1825 and 1826 ; but the recognition of the uterine nature of the disease deterred the operators from proceeding further. It was reserved for Dr. Clay of Manchester-whose claims as the pioneer of ovariotomy in this country have, by the way, not been sufficiently recognisea in some quarters-to lead the way in this matter also, by his operation in August 1843. For several years, the operations were "few and far between", and invariably with a fatal result; and it was ten years ere a success was scored. America claims this in the case of Burnham, and, with those of Kimball and Boyd, has the credit of the first three. Nearly twenty years elapsed ere a successful case occurred in this country ; and this, again, falls to the credit of Dr. Clay. Here, however, it is right that I should mention that, in $185 \mathrm{I}, \mathrm{Mr}$. Baker Brown, after removing a multilocular tumour of the right ovary, successfully cut away a small pediculated fibroid, the size of a hen's egg. For the first twenty years, the operations averaged about one a year; and it is a curious fact that these operations, with one exception, were the result of an error of diagnosis ; the operator, in each case, believing he had to deal with an ovarian tumour. According to Péan, the history of this operation comprehends three distinct periods. "In the first, which extends to 1843 , surgeons meeting with fibroid or fibrocystic tumours of the uterus instead of ovarian cysts recoiled before the consequences of amputation of the uterus, and did not complete the operation." In the second, which he calls the period of attempts and gropings, and which comes down to 1863 , "surgeons, emboldened by a more extended practice of ovariotomy, and encouraged by the success obtained in cases complicated by adhesions, which at first it seemed impossible to overcome, took a step in advance, and no longer feared to take away the body of the uterus whenever an error of diagnosis placed them in presence of a tumour in intimate connection with this organ. They were, as it were, compelled to improvise the operation, everything having been disposed for an ordinary ovariotomy. In the third, the operation entered on a new phase. In the month of April 1863, Kœberlé, finding himself in presence of a doubtful tumour, made arrangements for any eventuality; he practised gastrotomy, determined not to recoil even if, in urder to remove the whole of the tumour, he should be obliged to have recourse to supravaginal amputation of the uterus. His courage was rewarded with success."

On this last point, however, there is some conflict; for, whilst Péan claims for Kicberlé the honour of the first operation after a more or less correct diagnosis, others claim this honour for Kimball. Kimball's case occurred in 1853, and therefore ten years anterior to Kœberlé's.

However this may be, it is a fact that the results of the operation for well nigh thirty years were a fearful mortality, and it was not till ten or twelve years ago that this operation can be said to have been placed on a footing at all creditable to surgery; and we must assign the honour of this to the distinguished French surgeon, Péan. From September 1869 to February 1872 , Péan operated nine times, with the very gratifying result of seven recoveries. I know not what Péan's statistics are now, but up to April 1875 they presented a marked contrast to anything done in this country on a large scale to the same date, viz., a mortality of only 29 . I per cent., out of 24 cases-a result which I believe was due to his mode of performing the operation-specifically his treatment of the pedicle. Still the general mortality was very great. In I875, Dr. Samuel Pozzi collected a series of I 19 cases, with a mortality of 64.7 per cent. In 1879 , Dr. Letousey published a further series of 84 cases, with a mortality of 42.8 per cent. And even so recently as two years ago, viz., at the Cambridge meeting of this Asso. ciation, Mr. Spencer Wells stated that he had completed the operation in 34 out of 60 cases, in which he had opened the abdomen to find a fibroid or fibrocystic tumour of the uterus, and of these 18 died, and only 16 recovered, or a mortality of 52.9 per cent. But there were bright spots on this hitherto dark picture, for Keith was, in his quiet way, operating with his usual success; with such success that up the present time he has lost only one out of 12 cases, and in 1879 Dr. Thomas Savage (of Birmingham), published a series of 6 cases with 5 recoveries ; a very encouraging result, though somewhat discounted by a reference, in the same paper, to two cases previously done, with a fatal result.

This is not the occasion, nor will time permit me, to enter on the history, symptoms, diagnosis, progress, and termination of fibroid or fibrocystic tumours of the uterus, or to enter on a comparison of the relative merits of hysterectomy and oöphorectomy so dear to the heart of Mr. Lawson Tait. Perhaps, I ought to apologise to Mr. Tait for associating his name with the term oöphorectomy. I use it for brevity's sake, and must be understood as implying what he prefers to call the "Removal of the Uterine Appendages." Suffice it to say that, while on the one hand, it is allowed that fibroid tumours do not often kill, that they have not that fatal tendency which is so characteristic of the ovarian, on the other hand it is now admitted that there are certain cases, and in not a small proportion, in which this operation affords the only hope of relief from very distressing symptoms, or even of averting death. Such are the cases of true fibro-cyst, of cystiform degeneration of a hard fibroid, of cases in which pain is the predominant symptom, and a few in which hæmorrhage threatens the life of the patient, or this combined with pressure on important viscera. It must be obvious that in most of these cases the removal of the uterine appendages can be of no service.

If any one were asked to name the most characteristic symptom of uterine fibroid, he would probably answer " hæmorrhage." But it is a remarkable fact that in only 4 of the 21 cases in which I have operated was this a prominent symptom at the time of operation. In one case, of which I show you a photograph, menorrhagia had been at one time so severe as to produce very marked anæmia, but the patient had recovered from this condition, and the operation was undertaken for the relief of pain. The explanation of this hæmorrhage will be found in the presence of a large mucous polypus, and the pain was probaibly due to the intestinal adhesions and pressure. In one case the pressure was such as to produce great œdema of the lower extremities, and albuminuria to the extent of one-third, which, with profound anæmia, pre. sented no very inviting prospect to the operator.

One does not usually associate the idea of adhesions with fibroid tumour; yet there were adhesions in no fewer than 9 of my 21 cases. In one, the adhesions were universal; viz., to the parietes, omentum, and intestines, and the intestines were adherent to one another, and to the parietes; in three there were adhesions of the omentum only, in two the adhesions were intestinal only, in two pelvic only, and in one they were omental and intestinal.

Every one who knows anything of fibroid tumours, will agree with me that it is not every case that is suitable for operation-assuming that the symptoms are serious-ard chiefly because of the relations of the growth to the pelvic contents. I may also say that I have myself refused to operate in several cases that seemed most favourable for operation, because the symptoms were not such as to justify me in urging such a proceeding. A tumour which grows out laterally from the uterus, and carries with it the broad ligament, offers insuperable difficulties in the control of hæmorrhage; or when the disease encroaches on, or actually involves, the vaginal portion of the cervix. Such cases, if attended with severe hæmorrhage, must be left to the doubtful benefit of oöphorectomy. Hence there must of necessity be a certain 
amount of selection, not all in favour of the operator. Yet, with the method I now follow, I am able to do cases that I should not have dreamed of touching two years ago. It is a simple matter when one has to deal with a small pedicle springing from the fundus or free surface of the uterus, as in a case reported by Dr. Godson before the Obstetrical Society of London for Mr. Wells, in which a small tumour was torn away from the back of the uterus without any hæmorrhage resulting; or as in some cases more recently reported by $\mathrm{Mr}$. Wells, in which the uterine body, though more or less involved, was quite healthy, and of normal size. But it is a very different matter when the pedicle is as thick as your wrist, or thicker, or where there is fibroid degeneration of the uterine body, or the tumour involves the whole of the uterine body, and the base of the tumour measures twelve inches on the cut surface, as in my twentieth case, of which $I$ here show you a drawing. I well remember the first case in which I opened the abdomen, many years ago, to find that I had mistaken a soft fibroid of the uterus for an ovarian tumour, only to close it again on recognising the uterine origin of the tumour, and its broad base. I should not now leave such a case unfinished; yet, two years ago, I should not have dared to proceed with many of the cases in the table.

I have quoted Péan to the effect that up to a certain period the operation was the result of an error of diagnosis. It is only very recently that this reproach no longer applied so widely. In my second case, the operation was undertaken for a supposed ovarian tumour; but this was very excusable, seeing that the patient had been already tapped, and that there was a large cyst with very thin walls anteriorly, with all the solid matter beyond reach, and a good pedicle from the fundus of the uterus. In another, the removal of the uterine body with some small fibroids was a necessity of the case, and due to the injury inflicted on the uterus in the separation of one of the ovarian tumours. In a third case, the intention was to perform oöphorectomy for the arrest of hæmorrhage, as the tumour encroached so much on the cervix that I dared not contemplate hysterectomy primarily; but insuperable difficulties with the left ovary compelled me to have recourse to supravaginal amputation. In all the other cases, the operation was undertaken with the specific intention of removing the tumour. Yet my twentieth case is a striking instance of error of diagnosis, for it was certified by a very distinguished surgeon as a multilocular ovarian tumour. In this instance, I suppuse, the elasticity was mistaken, as in many instances it has been, for fluctuation.

I now come to the operation itself. It is not necessary that I should dwell on those steps of the oferation that are common to it and ovariotomy. On these I need only remark that the incision must be in proportion to the size and nature of the tumour, an incision of four or five inches being made, first to ascertain the possibility of removing the tumour, and then enlarged as required. With regard to ovariotomy, tables have been constructed with the view of showing that a long incision is more dangerous than a short one; but this is only a curious example of reasoning from false premisses, the results having been attributed to the length of the incision rather than to the gravity of the case. In my experience, an incision of twelve inches has healed just as well as one of six. Adhesions must be separated and bleeding points secured, as in ovariotomy.

But when we come to the treatment of the pedicle, or of what stands for it, and which is often the uterine body itself, we come to the crucial point.

How, then, is the pedicle to be treated? When the pedicle is narrow, and springs from the fundus or free surface of the uterus, I believe it is immaterial whether it be treated by the intraperitoneal method, i.e., the ligature, or the extraperitoneal. If the ligature be used, care must be taken to ensure complete arrest of hæmorrhage. This is not always an easy matter, for such is the peculiar nature of the uterine tissues that they give way before the force of the ligature to such an extent, that in a few hours fatal bleeding may ensue. An additional precaution is at our command by dividing the pedicle in such a way as to get two flaps, which are brought together by interrupted or continuous suture. Mr. Wells, while strongly advocating the ligature in all cases, attributes to the bringing together of the peritoneal edges an importance which it does not possess; for he thinks its advantage lies in the covering over of the raw surface and shutting it out of the peritoneal cavity. He appears to me to miss the point of his own practice, which is rather the additional security against hæmorrhage. Who ever heard of anyone shutting out the raw surface of an ovarian pedicle? And yet, in thick pedicles, there is an extensive raw surface left. It would undoubtedly be an advantage if we could always treat the pedicle in hysterectomy by the intraperitoneal method, as it would very considerably shorten the period of convalescence.

When, on the other hand, the pedicle is very thick and vascular, no method of applying the ligature will suffice to secure' the patient against hæmorrhage. Now, it must not be supposed that $I$ have a prejudice against the ligature as such, seeing that I was the first in this country to revive and urge its systematic use in the treatment of the ovarian pedicle, and that I have adhered to it until I have the satisfaction of seeing its almost universal adoption. But, having treated my first case of hysterectomy in the very way since advocated by Mr. Wells, and with a fatal result in the way just indicated; having, moreover, seen hæmorrhage from stumps kept outside, that had been compressed by means of the serre-noud to an extent far exceeding the power of any man's pair of hands; bearing in mind that Hegar has returned to the extraperitoneal method with the most satisfactory result; that Keith has, up to the present time, lost only one out of twelve thus treated ; and that those who have adopted this method have had the best results, I should be ignoring the lessons of experience if, in deference to high authority, $I$ continued to rely on the ligature and the intraperitoneal method. That the practice suggested by Olshausen of applying an elastic ligature, and leaving it within the peritoneum to become encapsuled, will ever become at all general, I do not for a moment believe. Leaving the ordinary ligat ure to be absorbed, has been called an unsurgical proceeding, but surely this is the most unsurgical of all.

Péan employs Cintrat's instrument, which has this disadvantage : that the loop is twisted, and is not available for the arrest of hæmorrhage when the tissues have shrunk and the loop has become quite slack. This happened in the only case in which I used it, and I had not only to sear the surface several times with the actual cautery, but to untwist the wire and adapt it to Kœberle's instrument.

Hegar prefers the elastic ligature with the extraperitoneal method; but, as the principle is the same, I shall not quarrel with him on that account.

For my part, I prefer Kœberlé's serre-nœud, which has this advantage : that the constricting force is entirely under command. It is also very easy to apply, and is thoroughly efficient. Now, I do not claim any originality in this beyond the fact that, in the chaotic state of the treatment of the pedicle in this country at the time when I began, I stumbled upon it in my groping after a more reliable method than I had yet seen or read of. I had not seen Péan's memoir until quite recently, and it was only by private information that I had, also recently, learned Keith's method and results; for, with that modesty and reticence which are so characteristic of him, he has continued to "hide his light under a bushel".

In applying this instrument in a case of supravaginal hysterectomy, it is desirable to include the ovaries. Sometimes, however, this cannot be done, as the ovarian ligaments are too short, and then the ovaries must be ligatured separately. I have had to do this in two cases. As an instance of what can be done, I may again mention that, in my twentieth case, of which I have shown you a drawing, the cut surface from one ovary to the other measured twelve inches. Yet all this was readily brought together. After the loop is thoroughly tightened, the stump is transfixed close to the wire with two specially constructed pins with guarded points either before or after the tumour is cut away. In closing the wound, I take care to bring the peritoneum together as accurately as possible around the stump, and I have never seen any reason to regret the omission of separate stitches to keep the peritoneal surfaces together, considered so important by Hegar. In some cases, the drag on the stump is so great as to depress the surface below the level of the pubes, and it is remarkable how little trouble this occasions. It might be thought that disturbance of the bladder would be inevitable, but the parts seem able to accommodate themselves in a wonderful way, and it is not at all unusual to find the bladder contain at one time as much as eight or ten ounces of urine within the first twentyfour hours.

By the time the dressings are applied, it will be well to give an extra turn or so to the screw; and the facility with which this can be done will make more plain the source of danger when a thick pedicle is entrusted to the ligature. I think it unnecessary, if not injurious, to sear the surface' of the stump with the actual cautery or to apply perchloride of iron. The stump, surrounded with dry. absorbent gauze, dries up better without either of these.

The stump will be dressed as often as necessary. Should there be any discharge-and this will be in proportion to the drag on the pedicle and the amount of raw surface in connection with the dead portion of the stump-it may be kept free froni putrefaction by using a mixture of glycerine and rectified spirit in equal parts, either with or without 4 or 5 per cent. of eucalyptol. In from seven to fourteen days, according to the nature of the pedicle, the serre-noud may be removed, and in a day or two the pins, one at a time, and the stump trimmed. There will then be left a funnel-shaped depression, corresponding in breadth and depth to the size of the stump, the amount of dragging, and the thick- 
Cases of Hysterectomy in which the Pedicle was secured by Koeberle's Serre-Noud.

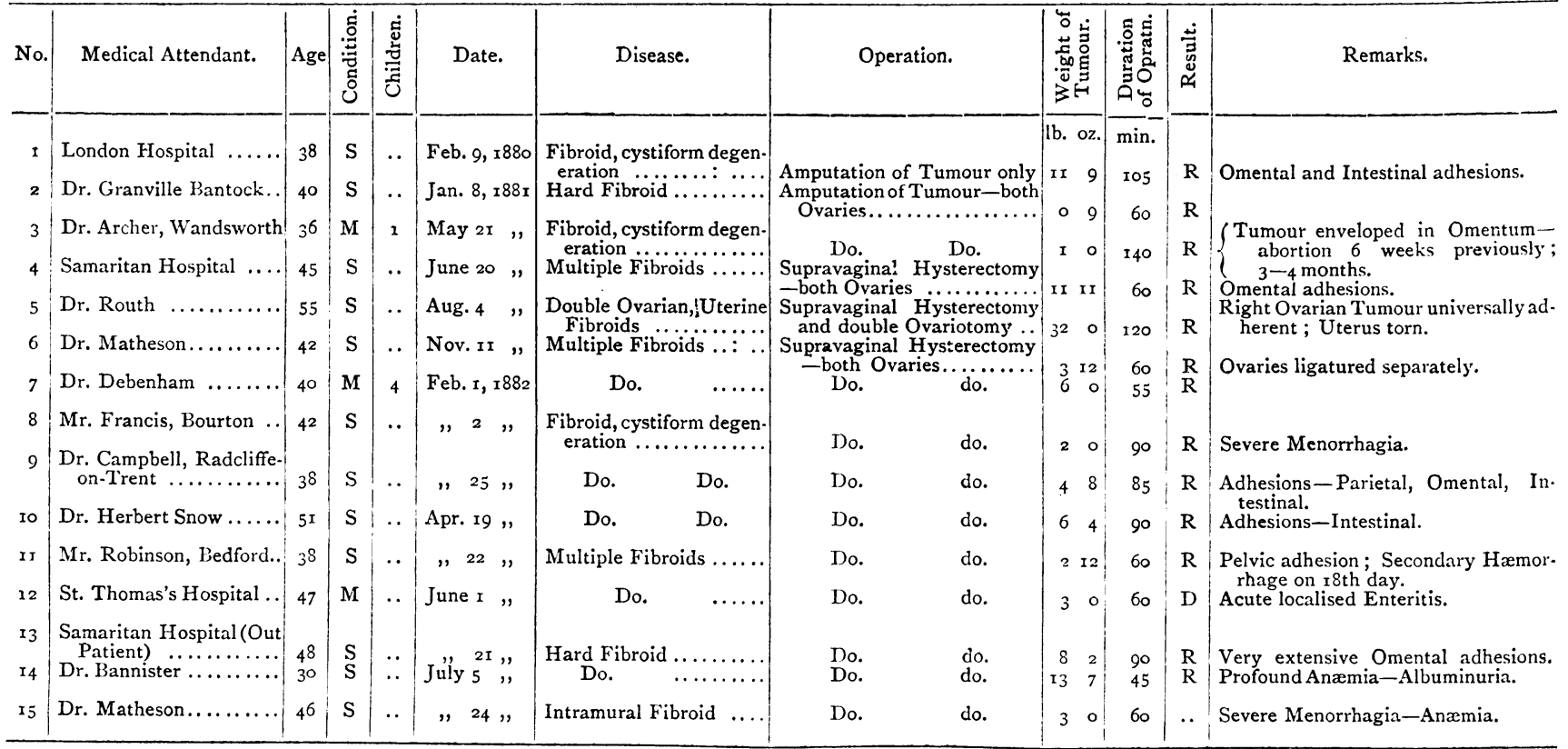

Other Cases of Hysterectomy.

\begin{tabular}{|c|c|c|c|c|c|c|c|c|c|c|c|}
\hline No. & Medical Attendant. & Age & : & Date. & Disease. & Operation. & Pedicle. & 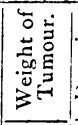 & 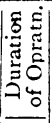 & 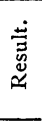 & Cause of Death, etc. \\
\hline & & & & & & & & lb. oz. & & & \\
\hline I & Dr. Turle............ & 27 & $\mathrm{~S}$ & & Fibroid, cystiform & & & & & & \\
\hline 2 & Dr. Wynn Williams .... & 32 & $\mathrm{~S}$ & June 30,1880 & Fibroids .. & Enucleation of Fibroid, and & Ligatures........ & 210 & 0 & U & $\begin{array}{l}\text { Shight oozing from stump-Sep- } \\
\text { ticæmia. }\end{array}$ \\
\hline 3 & Mr. Mapleson.... & 40 & $\mathbf{S}$ & Apr. I4, I 881 & Fibroid, cystiform & amputation of part of Uterus & Nœud on Uterus & $\left|\begin{array}{ll}3 & 8\end{array}\right|$ & 90 & $\mathrm{D}$ & $\begin{array}{l}\text { Hæmorrhage from broad liga- } \\
\text { ment ; drainage-tube-failure. }\end{array}$ \\
\hline 4 & $\begin{array}{c}\text { Samaritan Hospital (Out. } \\
\text { Patient) } \ldots \ldots \ldots \ldots \ldots\end{array}$ & 30 & $\mathbf{M}$ & July $13,$, & $\begin{array}{l}\text { degeneration... } \\
\text { Hard Fibroid .... }\end{array}$ & $\begin{array}{l}\text { Amputation at the Fundus.. } \\
\text { Amputation-one Ovary re. }\end{array}$ & Ligatures .... & $\begin{array}{ll}17 & 0\end{array} \mid$ & 100 & $\mathrm{D}$ & $\begin{array}{l}\text { Severe Intestinal adhesions- } \\
\text { obstruction. }\end{array}$ \\
\hline & & & & & & moved $\ldots \ldots \ldots \ldots \ldots \ldots$ & Ligatures........ & & 60 & $\mathrm{D}$ & $\begin{array}{l}\text { Hæmorrhage from stump ; small } \\
\text { pelvic adhesions. }\end{array}$ \\
\hline 5 & Gt. Northern Hospital - & 46 & $\mathbf{M}$ & Aug. 3 , & Two Fibro-cystic . & One removed, other drained. & Ligatures........ & & 85 & $\mathrm{R}$ & \\
\hline 6 & Dr. Granville Bantock.. & 48 & $\mathbf{M}$ & May 3 $3,1882^{1}$ & Soft Fibroid.. & $\begin{array}{r}\text { Partial Enucleation and Su- } \\
\text { pravaginal Hysterectomy }\end{array}$ & $\begin{array}{r}\text { Serre }- \text { Nœud on } \\
\text { Uterus } \ldots \ldots \ldots\end{array}$ & $\mid \begin{array}{ll}56 & 0\end{array}$ & 90 & $\mathrm{D}$ & $\begin{array}{l}\text { Acute Uræmia ( } 48 \text { hours); con } \\
\text { tracted Kidneys. }\end{array}$ \\
\hline
\end{tabular}

ness of the parietes. I have seen it in a stout subject two inches deep. This is dressed with the glycerine and spirit lotion, and after the separation of all dead tissue, the hole closes with scarcely a drop of pus. Care must be taken to make it granulate up from the bottom, so as to avoid a troublesome sinus.

I should not omit to mention a remarkable occurrence in my sixteenth case, No. I I of the first table. On the eighteenth day, when all dead tissue had come away, and there was a clean, healthy, granulating surface of small extent, alarming hæmorrhage took place from the stump and through the vagina. The time corresponded with the next menstrual period.

While, then, I admit that in the case of a small pedicle springing from the fundus or free surface of the uterus, the extra, or intraperitoneal method may, either of them, be employed according to the predilection of the operator, or even when the uterine body is somewhat involved, as in some cases reported last year by Mr. Wells, yet it is a very different thing where the relations of the tumour or tumours to the uterine body are such as to involve supra-vaginal amputation of that organ in order to remove the whole of the disease. While, also, I am aware of the strong advocacy of the intraperitoneal method by Wells, Schroeder, and Olshausen, the latter of whom has recently reported twelve cases, with eight recoveries and four deaths, or mortality of 33 per cent., with the aid of all the supposed advantages of "Listerism," yet, in such cases as these, I have no hesitation in affirming that the best results will be obtained by the extraperitoneal method. Such was the method adopted and consistently followed up by Péan, such also the method returned to by Hegar with the result that of twelve consecutive cases only one died; and such also the method adopted by Keith, as already stated. In all these the principle is the same, though the details vary. And when, finally, I tell you, what a glance at the tables will show you, that of fifteen cases treated exclusively in this way only one died, while of six treated otherwise, and chiefly by the lisrature, five died, I think I have strong grounds for the confidence with which I recommend this method, believing, as I do, that if a practice of which the principle has the sanction and recommendation of such men as Péan, Hegar, and Keith be carefully and intelligently followed, we, who are in the habit of operating, paying no heed to or even smiling at the fulminations of some men high in authority, shall yet see hysterectomy attain to a position as creditable to surgery, and as beneficial to suffering humanity, as that now held by its foster-mother, ovariotomy.

Dr. Dewar inquired the reason for operating in Dr. Bantock's cases, as he understood from the paper that there had been severe hæmorrhage in four cases only out of the twenty-one in which the operation had been performed.

Dr. EDIS (London) thought that, with such results as those of Dr. Bantock before us, it was plainly our duty, when patients with fibroid disease displayed very urgent symptoms, to set before them the chances of relief which surgery offered. He foresaw a time approaching when a medical man would almost be regarded as guilty of homicide if he neglected, under such circumstances, to propose to hand his patient over to someone who had made this operation his specialty.

Dr. JoHN WiLliams (London) said that he could not agree with the remarks that had fallen from Dr. Edis. There was a very large num. 
ber of women, the subjects of fibroid disease of the uterus, who went about presenting no symptoms of any kind. There was another large number who presented only slight symptoms, and there were some who suffered severely. In many of them, the hæmorrhage could be controlled. In four only of Dr. Bantock's cases was hæmorrhage present. It was not stated why the operation was undertaken, but doubtless the reasons were sufficient. Out of the twenty-one cases, there were six deaths, representing a mortality of nearly 30 per cent. Dr. Williams thought that the cases which called for operation were not numerous. He had done it four times, with three recoveries. In the case which died, the fibroid weighed $28 \mathrm{lbs}$; the broad ligaments were tied in sections, and the neck of the uterus secured with whipcord. Death was occasioned by hæmorrhage from the ovarian artery. $\mathrm{He}$ had not himself seen contraction of the uterine stump and loosening of the ligature.

Dr. RouTH (London) w 2 s struck by the statement of the last speaker with reference to the slipping of the ligature. In his (Dr. Routh's) Lettsomian lectures, he had collected a large number of cases of removal of fibroids of the uterus, some of them being instances of mistaken diagnosis. In several of the fatal cases, the result was due to this slipping of the ligature, of the liability of which Dr. Bantock had spoken. When the pedicle had been transfixed, this had not occurred. Hence the practical advantage of first transfixing by needles. $\mathrm{He}$ thought Kœberlé's small écraseur was a most excellent instrument. If, as he had himself observed in Dr. Bantock's cases, the ecraseur could be tightened fifteen minutes after the operation, it showed that simple ligature was insufficient. He considered it essential that transfixion should be employed, and that Kœberlé's instrument should also be used to constrict the tissues. Lastly, he could not suppose that in all his cases Dr. Bantock had operated without exercising judgment. If the mortality was great, it was because the cases sent to Dr. Bantock were such as were incurable by any other means. This must be the case whenever men become noted in connection with any special operation. That with such unpromising cases Dr. Bantock had been so: successful was, he considered, matter for encouragement and congratulation.

Dr. WALLACE (Liverpool) remarked that in Liverpool he had a large field of observation, and saw a considerable number of fibro-cystic uterine tumours yearly. He had operated several times when driven to do so by the urgency of the symptoms, rendering the patient unable to perform her duties, or threatening her life. But he did so with reluctance, seeing that the whole tendency of the life history of these growths was to recovery, and that he had never seen a patient die from them. $\mathrm{He}$ mentioned a case in which he thought Dr. Bantock's method would not have answered. He removed the tumour, ligaturing the vessels as they were opened. A flap was reflected from the lower third of the tumour, which was enucleated, twisted, brought outside the parietal wound, and clamped. The serre-naud would not have been applicable, and if it would, it must have been left in the peritoneal cavity.

Dr. BANTOCK, in reply, said that he considered that, even in the absence of profuse hæmorrhage, it was a surgeon's duty to give what relief was in his power in cases where the pain was so severe as to entirely incapacitate the patients. With regard to the liability of the uterine tissues to shrink, and the ligatures to become thereby loosened, he could assure Dr. Williams that a larger experience would convince him of the reality of the danger.

\section{OBSTETRIC MEMORANDA.}

\section{PLACENTA PRAVIA.}

ON Sunday last, I was called to a labour-to all appearance normal. Examination per vaginam detected the placenta, extending for some distance across a semidilated os uteri on the anterior aspect, so that it must have been detached from the posterior part of the uterus; the bag of membranes bulged behind this during the pains. Having intentionally lacerated the placenta to some extent, with the result of but covering my finger with blood, I ruptured the membranes, when only a little blood escaped, or rather a flow of liquor amnii streaked with blood. As the head descended pretty quickly by acting on the uterus, and as no hæmorrhage of importance occurred in the intervals between the pains, I considered it safe to allow the labour to be terminated without aid, unless occasion should offer when the forceps could ter minate it without delay. About three hours after I first saw the patient, and with no other aid save external manipulation, the mother, a primipara, gave birth to a strong female child. The placenta was soon expelled, but the uterus still felt like a large doughy mass; but soon after the expulsion of about a pint (not measured) of blood, firm contraction of the uterus resulted. The case has progressed favourably. The placenta was healthy, and was lacerated over a surface of about two by three inches.

This is one of the many cases which militate against Simpson's theory of hæmorrhage in placenta prævia, and may also add some additional force to the objections against meddlesome midwifery.

$$
\text { f John Reid, M.A., M.B., C.M., Rochdale. }
$$

\section{PROLONGED USE OF CHLOROFORM IN INSTRUMENTAL} LABOUR.

ON August 6 th, 1878, I was sent for to a case of labour at full time, when I found the os dilating and vertex presenting; I also found antero-posterior deformity. The promontory of the sacrum projected a good deal forward, but the brim was not narrower than I have frequently delivered a living child through, at full time, with the long forceps. After some hours, I found the os fully dilated, labour-pains strong, and the head becoming impacted. I thereupon applied the long forceps, and endeavoured to extract under chloroform, but ineffectually. I then called in a neighbouring practitioner, who also thought he could deliver with the long forceps, but failed. I then performed craniotomy, using Simpson's perforator freely, and breaking up the cerebral substance, and afterwards using craniotomy-forceps, crotchet, etc., but all to no purpose. The base of the skull was so much ossified and so large, that we could not move it, though we applied the long forceps over it, and again endeavoured to extract, injecting tepid water, etc.

We then called in a third doctor, who also failed, after repeated trials. We finally arranged to perform Cæsarean section if another endeavour to deliver by the forceps failed. The patient was then fully anæsthetised, and held firmly by my two brethren and a nurse, while I again applied the forceps and made very forcible traction, when I was delighted to feel the head yield, and effect the delivery of a very large male child.

As soon as the chlorcform sleep passed off, we gave a pill, with two grains of opium, and repeated it daily for a few days, syringing with a weak tepid antiseptic injection. The patient made an excellent recovery, without a single alarming symptom.

What I desire to point out in reference to this case is, that for over six hours (from 4 A.M. to IO. 30 A.M.) the patient was almost continuously under the influence of chloroform; that she had no excessive post partum hæmorrhage, no vomiting, no nervous shock ; and that her recovery was almost as rapid, and fully as perfect, as in the most favourable case of natural labour. These good results I attribute largely to the free and full and prolonged administration of chloroform. I fear that ether would have a greater tendency to favour post partum hæmorrhage, and induce vomiting. I have, however, never used ether during my obstetric operations, but chloroform I have repeatedly used in my midwifery practice, and sometimes in prolonged cases, and have never found the slightest ill results to follow its use.

I gave the details of this case to my friend Dr. L. H. Ormsby, and I was glad to see, by a letter he subsequently wrote on the subject in the JOURNAL, that he specially excepts obstetric practice when he contends for the superiority of ether over chloroform as an anæsthetic.

\section{J. Wybrants OlPherTs, L.M., L.R.C.P.E.} Certifying Factory Surgeon for Lurgan, etc.

\section{TROUBLESOME LABOURS.}

PERHAPS the following four successive cases of midwifery may be of interest.

CASE I.-On July Ist, I was called in to attend a Mrs. P. in her first confinement. I found the patient reclining on the bed in great agony. The os uteri was fully dilated; and I was much puzzled at feeling, instead of a fotal head, a large, soft, fluctuating mass. Being feeling, instead the case, I sent for my partner (Mr. Orfend of West Town), who, after making an examination, came to the conclusion that some portion of the child's back was presenting, and recommended turning. I therefore administered chloroform; and, after about one hour's manipulation, my partner succeeded in extracting, with some difficulty, a male child (dead), with a hydrocephalic head. In this case, the presentation was natural; but the state of the head caused the deception. The mother in this case made a rapid recovery.

CASE II.-On July $30 t h$, I was sent for to attend a Mrs. B. in her second confinement (her first child having been born six years previously). The nature of the case necessitated the use of forceps; but, it was only after using considerable force, that I was enabled to bring the head of the child into the world; and I awaited the natural expulsive powers of the uterus to complete the delivery. I was surprised, however, to find that, notwithstanding the sharp pains the woman 